\title{
A NEW SPECIES OF RHINOGOBIUS GILL, 1859 (TELEOSTEI: GOBIIDAE) FROM THE BONIN ISLANDS, JAPAN
}

\author{
Toshiyuki Suzuki \\ Kawanishi-midoridai Senior High School, 1-8 Kouyoudai, Kawanishi, Hyogo 666-0115, Japan. \\ I-Shiung Chen \\ Institute of Marine Biology \& CMBB, National Taiwan Ocean University, Keelung 202, Taiwan, ROC., isc@ntou.edu.tw \\ Hiroshi Senou \\ Kanagawa Prefectural Museum of Natural History, 499, Iryuda, Odawara, Kanagawa 250-0031, Japan.
}

Follow this and additional works at: https://jmstt.ntou.edu.tw/journal

Part of the Engineering Commons

\section{Recommended Citation}

Suzuki, Toshiyuki; Chen, I-Shiung; and Senou, Hiroshi (2011) "A NEW SPECIES OF RHINOGOBIUS GILL, 1859

(TELEOSTEI: GOBIIDAE) FROM THE BONIN ISLANDS, JAPAN," Journal of Marine Science and Technology. Vol. 19: Iss. 6, Article 15.

DOI: $10.51400 / 2709-6998.2213$

Available at: https://jmstt.ntou.edu.tw/journal/vol19/iss6/15

This Research Article is brought to you for free and open access by Journal of Marine Science and Technology. It has been accepted for inclusion in Journal of Marine Science and Technology by an authorized editor of Journal of Marine Science and Technology. 


\section{A NEW SPECIES OF RHINOGOBIUS GILL, 1859 (TELEOSTEI: GOBIIDAE) FROM THE BONIN ISLANDS, JAPAN}

\section{Acknowledgements}

We are very grateful to G. Fukagawa (Nagasaki Food Hygiene Assciatio), K. Hatooka (OMNH), A. Iwata (Kyoto University), T. Mukai (Gifu University) for their kind cooperation in the present study. We are also very grateful to K. Tamada (Toyo Public Junior High School, Japan) for his kindly providing his unpublished oocyte data of Rhinogobius brunneus for the comparison of this research. ISC wishes to thank the support from the research grant of NSC, Taipei. 


\title{
A NEW SPECIES OF RHINOGOBIUS GILL, 1859 (TELEOSTEI: GOBIIDAE) FROM THE BONIN ISLANDS, JAPAN
}

\author{
Toshiyuki Suzuki*, I-Shiung Chen**, and Hiroshi Senou***
}

Key words: Gobiidae, Rhinogobius ogasawaraensis sp. nov., egg size, amphidromous, fish taxonomy, West Pacific.

\section{ABSTRACT}

A new freshwater goby, Rhinogobius ogasawaraensis was collected from streams of the Bonin Islands (Ogasawara Group), Japan. The species can be distinguished from all congeneric species by the following combination of characters: (1) meristic features: second dorsal fin rays I, 8-9; pectoral fin rays 18-20; predorsal scales 7-16; longitudinal scale rows usually 32-34; vertebral count 26; and (2) specific colouration: check with some red spots, nape with several longitudinal dark stripes, upper part of pectoral fin base with a horizontal deep brown bar, intermittent dark dotted rows along middle axis of body, no saddle shaped patch of dark dots on dorsal side of body, ventral side of body yellowish white, caudal fin with some dark dotted rows on middle region and the base with a pair of dark brown bars which vertically to each other. The ripe oocyte diameter of this new species suggests that it belongs to a member of typical amphidromous species.

\section{INTRODUCTION}

The Asiatic freshwater goby genus Rhinogobius Gill, 1859 [16] is widely distributed on islands of the West Pacific, including Japan (Akihito et al. [1, 2]; Masuda et al. [24]); Taiwan (Aonuma and Chen [3]; Chen and Shao [13]; Lee and Chang [22]; Chen et al. [11]); Hainan (Wu and Ni [50]; Chen et al. [12]); and the Philippines (Herre [18]; Chen in preparation), and also in continental Asia in Russia, Korea, China, Vietnam, Laos, Cambodia, and Thailand (Kottelat [21]; Chen and Miller [10]; Chen et al. [9, 14, 15]; Chen and Kottelat [6, 7,

Paper submitted 09/27/10; revised 05/12/11, accepted 05/12/11. Author for correspondence: I-Shiung Chen (e-mail: isc@ntou.edu.tw).

*Kawanishi-midoridai Senior High School, 1-8 Kouyoudai, Kawanishi, Hyogo 666-0115, Japan.

**Institute of Marine Biology \& CMBB, National Taiwan Ocean University, Keelung 202, Taiwan, ROC

***Kanagawa Prefectural Museum of Natural History, 499, Iryuda, Odawara, Kanagawa 250-0031, Japan.
8]; Chen and Fang [5]; Huang and Chen [19]). The life histories of Rhinogobius species indicate that the genus comprises amphidromous species, nondiadromous, fluvial species and lentic species (Mizuno [26]; Mizuno and Goto [27]; Takahashi and Okazaki [42]; Akihito et al. [2]).

In Japan, there are at least 15 discrete species have been recorded and accounted including $R$. flumineus (Mizuno, 1960 [26]), R. giurinus (Rutter, 1897 [33]), R. sp. BB (Blue belly), $R$. sp. BF (Banded fin), R. sp. BI (Bonin Islands), R. sp. BW (Lake Biwa), $R$. sp. CB (Cross band), $R$. sp. CO (Cobalt), $R$. sp. DA (Dark), $R$. sp. DL (Depressed large dark), R. sp. LD (Large dark), $R$. sp. MO (Mosaic), $R$. sp. OR (Orange), $R$. sp. TO (Tokai), and $R$. sp. YB (Yellow belly). They can be grouped in $R$. brunneus (Temminck and Schelegel, 1845 [47]) species complex with normal vertebral count 26 except the fluvial species of $R$. flumineus (Mizuno, 1960 [26]) as high vertebral count up to 27-28 and R. giurinus (Akihito et al. [2]; Suzuki et al. [39]; Suzuki and Sakamoto [40]; Suzuki and Shibukawa [41]; Takahashi and Okazaki [42]). In Taiwan, all nine nominal Rhinogobius species are endemic to the island including except $R$. giurinus (Lee and Chang [22]; Chen and Shao [13]; Chen and Fang [4]).

There are seven nominal species of Rhinogobius which have been described so far in Japan: $R$. brunneus (Temmick and Schelegel) from Bay of Nagasaki, Nagasaki Pref., the East China Sea coast of Kyushu; R. similis Gill, 1859 [16] from Shimoda, Izu Prov., Shizuoka Pref., the Pacific coast of Honshu; R. nagoyae Jordan \& Seale, 1906 [20] from Nagoya, Aichi Pref., the Pacific coast of Honshu; R. kurodai (Tanaka, 1908 [45]) from Tokyo Pref., the Pacific coast of Honshu; R. katonis (Tanaka, 1908 [45]) from Kanazawa, Ishikawa Pref., the Sea of Japan coast of Honshu; $R$. fluviatilis Tanaka, 1925 [46] from Himeji, Hyogo Pref., the coast of the Inland Sea of Seto in Honshu. R. flumineus from Sôshagawa R., Ehime Pref., Shikoku.

More recently in early 2011, Oijen et al. [29] have concluded that $R$. sp. DA should be regarded as the earliest published species for the genus, $R$. brunneus; Suzuki and Chen [41] have re-described that both $R$. sp. LD and $R$. sp. OR should be grouped as $R$. fluviatilis and $R$. kurodai respectively.

In Taiwanese waters, nine endemic nominal species of Rhinogobius have been described including as follows: 
R. candidianus (Regan, 1908 [32]), R. formosanus Oshima, 1919 [30]; R. rubromaculatus Lee and Chang, 1996 [22]; $R$. gigas Aonuma and Chen, 1996 [3]; R. nantaiensis Aonuma and Chen, 1996 [3]; R. maculafasciatus Chen and Shao, 1996 [13]; R. delicatus Chen and Shao, 1996 [13]; R. henchuenensis Chen and Shao, 1996 [13]; and R. lanyuensis Chen et al., 1998 [11].

So-called, "Ogawasawa-yosinobori", $R$. sp. BI is regarded as the "Bonin Islands (Ogasawara group)"-endemic species to be distributed over the Anijima Island, Chichijima Islands, Hahajima Islands and Ootouto Island. $R$. sp. BI is endangered amphidromous goby, and is distinguished from other Japanese Rhinogobius complex [34-36, 51-54].

Furthermore, Mukai et al. [28] investigated the mitogenetic differentiation between $R$. sp. BI and other congeneric species of the Japan-Ryukyu Archipelagos, and concluded that it has retained its own mtDNA lineage in Ogasawara Group for millions of years.

However, those nominal species are known only from major Japanese Islands, Korean Peninsula and even Taiwan but are never recorded and distributed around the far away area: Bonin Islands (Ogasawara Group). Also R. giurinus is distributed on major Japanese Islands and the Ryukyu Islands but it has never distributed over Bonin Islands (Ogasawara Group).

The aim of this paper is to formally describe $R$. sp. BI as a new species under the specific name of $R$. ogasawaraensis.

\section{MATERIALS AND METHODS}

All type specimens of the new species were collected by hand-net. All counts and measurements were made from specimens preserved in 70\% ethanol. Morphmoetric methods follow Miller [25] and meristic methods follow Akihito et al. [1], Chen and Shao [10] and Chen et al. [9, 14, 15]. Terminology of cephalic sensory canals and free neuromast organ (sensory papillae) is from Wongrat and Miller [46], based on Sanzo [33]. The oocyte diameter from this new species and 4 typically amphidromous species with small-egg size of Taiwan were measured under the microscope by sampling from adult females. Type specimens are deposited at the Osaka Museum of Natural History, Osaka (OMNH), Japan; Kanagawa Prefectural Museum of Natural History, Kanagawa (KPM), Japan and the Pisces collection of Institute of Marine Biology, National Taiwan Ocean University, Keelung (NTOU P), Taiwan. Meristic abbreviations: A, anal fin; C, caudal fin; D1, and D2, 1st and 2nd dorsal fins respectively; LR, longitudinal scale series; $\mathrm{P}$, pectoral fin; PreD, predorsal scales; SDP, scale series from origin of 1st dorsal fin to upper pectoral fin origin.; TR, transverse scale series from second dorsal to anal fins; V, pelvic fin; VC, vertebral count. All fish lengths are standard length (SL). Colour when fresh is based on the photographs in the Image Database of Fishes in the Kanagawa Prefectural Museum of Natural History (KPM-NR).

\section{SYSTEMATICS}

\section{Rhinogobius Gill, 1859 Rhinogobius ogasawaraensis sp. nov.}

(Japanese name: Ogasawara-yoshinobori)

(Table 1; Figs. 1-5)

Rhinogobius sp. BI Suzuki, 1992 [35]: 5 (Chichijima Island); Masuda and Kobayashi 1994 [23]: 378 (Ogasawara Group); Suzuki, 2001 [36]: 589 (Chichijima Island and Hahajima Island); Suzuki, 2003 [37]: 134 (Anijima Isand, Chichijima Island and Hahajima Island); Yokoi and Hosoya, 2003 [52]: 9 (Chichijima Island and Hahajima Island); Suzuki and Shibukawa, 2004 [41]: 454 (Anijima Isand, Chichijima Island and Hahajima Island); Yokoi, 2009 [51]: 145 (Chichijima Island, Hahajima Island and Otoutojima Island); Yokoi et al., 2009 [54]: 67 (Anijima Island, Chichijima Island, Hahajima Island and Otoutojima Island).

\section{Material examined}

Holotype: OMNH-P 8278, 65.1 mm SL, Yatsusegawa River, Chichijima Island, the Bonin Islands (Ogasawara Group), Japan, coll. T. Suzuki \& M. Suzuki, 30 July 1992.

Paratypes: NTOU P 2007-02-882 \& 2007-02-883, 2 specimens, 39.9-46.5 mm SL, A small stream of Oki village, Hahajima Ialand, the Bonin Islands (Ogasawara Group), Japan, coll. T. Mukai, 24 November 2001; KPM-NI 3839-3845 (KPM-NR 52867-52873) \& 3846, 30 specimens, 15.9-49.7 $\mathrm{mm}$ SL, coll. H. Senou, 3 July 1997, other data same as holotype; OMNH-P 8256 (KPM-NR 702), 1 specimen, $29.8 \mathrm{~mm}$ SL, Minamifukurozawa stream, 26 July 1992, other data same as holotype; OMNH-P 8257 (KPM-NR 741) \& 8258, 2 specimens, 32.3-35.5 mm SL, A small stream of Ohmura village, 28 July 1992, other data same as holotype; OMNH-P 8259-8261 (KPM-NR 746-748), 3 specimens, 40.1-43.5 mm SL, Okumugawa River, 28 July 1992, other data same as holotype; OMNH-P 8262 (KPM-NR 773), 8263-8270, 8274-8277 \& holotype; OMNH-P 8272, 1 specimen, $53.8 \mathrm{~mm}$ SL, A small stream of Sakaiura 8279-8282, 17 specimens, 36.7-75.2 mm SL, 30 July 1992, other data same as village, 1 August 1992, other data same as holotype; OMNH-P 8273, 1 specimen, 53.6 mm SL, 1 August 1992, other data same as holotype.

\section{Diagnosis}

Rhinogobius ogasawaraensis is distinguished from all congeneric species by the following unique combination of features: second dorsal fin rays I, 8-9, pectoral fin rays 18-20, predorsal scales $7-16$, vertebral count 26 , cheek with some red spots, nape with several longitudinal dark stripes, upper part of pectoral fin base with a dark blotch, intermittent dark dotted rows along middle axis of body, no saddle shaped patch of dark dots on dorsal side of body, ventral side of body yellowish white, caudal fin with some dark dotted rows on middle region and the base with a pair of dark brown bars which vertically to each other.

\section{Description}

Body rather cylindrical anteriorly, compressed posteriorly. 
Table 1. Morphometry of Rhinogobius ogawasaraensis n. sp.

\begin{tabular}{|c|c|c|c|c|c|c|c|c|c|}
\hline \multicolumn{5}{|c|}{ Holotype } & \multicolumn{4}{|c|}{ Paratypes } & \multirow{5}{*}{ STD } \\
\hline Sex & Male & & Male & & & & Female & & \\
\hline No. of specimens & 1 & & 15 & & & & 9 & & \\
\hline & & $\min$ & $\max$ & Mean & STD & $\min$ & $\max$ & Mean & \\
\hline $\mathrm{SL}(\mathrm{mm})$ & 65.1 & 43.5 & 75.2 & & & 29.8 & 63.8 & & \\
\hline \multicolumn{10}{|l|}{$\%$ in SL } \\
\hline Head length & $30.3 \%$ & $29.6 \%$ & $34.2 \%$ & $31.7 \%$ & $1.5 \%$ & $26.5 \%$ & $30.0 \%$ & $28.0 \%$ & $1.2 \%$ \\
\hline Predorsal length & $40.5 \%$ & $37.8 \%$ & $41.6 \%$ & $40.1 \%$ & $1.0 \%$ & $36.9 \%$ & $41.0 \%$ & $38.9 \%$ & $1.3 \%$ \\
\hline Snout to 2 nd dorsal origin & $60.4 \%$ & $55.8 \%$ & $61.4 \%$ & $59.7 \%$ & $1.3 \%$ & $57.1 \%$ & $61.7 \%$ & $59.9 \%$ & $1.4 \%$ \\
\hline Snout to anus & $59.3 \%$ & $55.5 \%$ & $61.6 \%$ & $58.6 \%$ & $1.6 \%$ & $55.0 \%$ & $60.3 \%$ & $58.3 \%$ & $1.9 \%$ \\
\hline Snout to anal fin origin & $63.1 \%$ & $61.0 \%$ & $64.7 \%$ & $62.9 \%$ & $1.1 \%$ & $59.4 \%$ & $64.5 \%$ & $62.5 \%$ & $1.8 \%$ \\
\hline Prepelvic length & $29.7 \%$ & $28.6 \%$ & $32.2 \%$ & $30.5 \%$ & $1.0 \%$ & $25.0 \%$ & $28.7 \%$ & $27.1 \%$ & $1.2 \%$ \\
\hline Caudal peduncle length & $24.9 \%$ & $23.3 \%$ & $26.0 \%$ & $24.8 \%$ & $0.8 \%$ & $23.9 \%$ & $28.2 \%$ & $25.7 \%$ & $1.4 \%$ \\
\hline Caudal peduncle depth & $12.7 \%$ & $12.1 \%$ & $14.0 \%$ & $12.8 \%$ & $0.6 \%$ & $10.9 \%$ & $12.8 \%$ & $12.1 \%$ & $0.6 \%$ \\
\hline 1st dorsal fin base & $14.0 \%$ & $14.0 \%$ & $17.6 \%$ & $15.5 \%$ & $1.0 \%$ & $12.8 \%$ & $16.2 \%$ & $14.9 \%$ & $1.2 \%$ \\
\hline length of longest D1 ray & $20.6 \%$ & $17.9 \%$ & $29.1 \%$ & $23.6 \%$ & $3.4 \%$ & $10.7 \%$ & $16.7 \%$ & $13.8 \%$ & $1.8 \%$ \\
\hline 2nd dorsal fin base & $16.8 \%$ & $15.9 \%$ & $18.5 \%$ & $17.3 \%$ & $0.8 \%$ & $14.6 \%$ & $17.2 \%$ & $15.9 \%$ & $0.8 \%$ \\
\hline Length of last D2 ray & $17.8 \%$ & $16.5 \%$ & $26.4 \%$ & $21.9 \%$ & $3.1 \%$ & $9.6 \%$ & $13.9 \%$ & $12.1 \%$ & $1.5 \%$ \\
\hline Anal fin base & $14.1 \%$ & $12.8 \%$ & $16.8 \%$ & $13.7 \%$ & $1.0 \%$ & $11.0 \%$ & $13.7 \%$ & $12.4 \%$ & $0.9 \%$ \\
\hline Caudal fin length & $21.7 \%$ & $21.7 \%$ & $28.2 \%$ & $25.4 \%$ & $2.0 \%$ & $21.6 \%$ & $25.8 \%$ & $23.5 \%$ & $1.4 \%$ \\
\hline Pectoral fin length & $19.5 \%$ & $19.5 \%$ & $25.8 \%$ & $22.7 \%$ & $1.8 \%$ & $21.4 \%$ & $26.7 \%$ & $23.1 \%$ & $1.5 \%$ \\
\hline Pelvic fin length & $13.0 \%$ & $11.1 \%$ & $16.3 \%$ & $14.3 \%$ & $1.4 \%$ & $12.8 \%$ & $17.3 \%$ & $14.9 \%$ & $1.5 \%$ \\
\hline Body depth of pelvic fin origin & $18.3 \%$ & $14.8 \%$ & $18.7 \%$ & $17.2 \%$ & $1.1 \%$ & $14.8 \%$ & $19.0 \%$ & $16.7 \%$ & $1.6 \%$ \\
\hline Body depth of anal fin origin & $15.9 \%$ & $14.3 \%$ & $17.6 \%$ & $15.6 \%$ & $1.0 \%$ & $13.7 \%$ & $17.5 \%$ & $15.2 \%$ & $1.1 \%$ \\
\hline Body width of anal fin origin & $13.7 \%$ & $9.8 \%$ & $14.7 \%$ & $12.3 \%$ & $1.3 \%$ & $10.7 \%$ & $14.6 \%$ & $12.8 \%$ & $1.5 \%$ \\
\hline Pelvic fin origin to anus & $30.6 \%$ & $26.3 \%$ & $32.3 \%$ & $29.5 \%$ & $2.0 \%$ & $25.0 \%$ & $34.1 \%$ & $31.6 \%$ & $2.8 \%$ \\
\hline \multicolumn{10}{|l|}{$\%$ in $\mathrm{HL}$} \\
\hline Snout length & $40.5 \%$ & $35.5 \%$ & $48.3 \%$ & $40.6 \%$ & $3.4 \%$ & $27.6 \%$ & $38.3 \%$ & $35.6 \%$ & $3.4 \%$ \\
\hline Eye diameter & $15.9 \%$ & $14.5 \%$ & $18.7 \%$ & $16.6 \%$ & $1.2 \%$ & $18.2 \%$ & $24.4 \%$ & $20.9 \%$ & $2.3 \%$ \\
\hline Postorbital length & $47.2 \%$ & $42.5 \%$ & $48.8 \%$ & $45.5 \%$ & $2.0 \%$ & $45.4 \%$ & $51.8 \%$ & $48.0 \%$ & $1.7 \%$ \\
\hline Cheek depth & $28.4 \%$ & $23.7 \%$ & $30.0 \%$ & $26.1 \%$ & $1.9 \%$ & $18.5 \%$ & $28.2 \%$ & $24.2 \%$ & $2.6 \%$ \\
\hline Head width in upper gill opening & $48.7 \%$ & $41.8 \%$ & $53.4 \%$ & $45.6 \%$ & $3.0 \%$ & $41.7 \%$ & $58.8 \%$ & $49.4 \%$ & $4.8 \%$ \\
\hline Head width in maximum & $56.3 \%$ & $52.7 \%$ & $64.0 \%$ & $56.9 \%$ & $3.1 \%$ & $53.1 \%$ & $73.9 \%$ & $61.9 \%$ & $6.0 \%$ \\
\hline Bony interorbital width & $6.2 \%$ & $5.8 \%$ & $10.4 \%$ & $7.7 \%$ & $1.2 \%$ & $5.6 \%$ & $9.6 \%$ & $7.7 \%$ & $1.2 \%$ \\
\hline Fleshy interorbital width & $35.6 \%$ & $28.0 \%$ & $36.3 \%$ & $33.0 \%$ & $2.3 \%$ & $33.2 \%$ & $40.6 \%$ & $37.4 \%$ & $2.2 \%$ \\
\hline Lower jaw length & $39.2 \%$ & $36.1 \%$ & $41.5 \%$ & $39.2 \%$ & $1.7 \%$ & $27.3 \%$ & $34.3 \%$ & $32.2 \%$ & $2.2 \%$ \\
\hline \multicolumn{10}{|l|}{$\%$ in Caudal peduncle length } \\
\hline Caudal peduncle depth & $51.2 \%$ & $47.2 \%$ & $53.5 \%$ & $51.1 \%$ & $2.1 \%$ & $43.1 \%$ & $51.5 \%$ & $47.1 \%$ & $3.0 \%$ \\
\hline
\end{tabular}

Head moderately large, slightly depressed in adult male and sub-cylindrical in female. Eye large, dorsal lateral. Cheek somewhat fleshy in male. Lips thick and fleshy, upper lip somewhat prominent than lower lip. Mouth oblique and the rear margin usually extending near vertical of anterior margin of eye in male, and not extending to the vertical in female. Both jaws with 3-5 rows of conical teeth and outer rows enlarged. Tongue margin somewhat truncate. Anterior nasal opening as a short tube and posterior one as a round hole. Gill-opening extending ventrally slightly beyond the midline vertical of opercle. Isthmus broad. $10+16=26$ vertebrae $(n=$ 10). Body proportions as Table 1 .

Fins. - D1 rays VI $(\mathrm{n}=28)$; D2 rays I, 8 (22), I, 9 (6) (modally I, 8); A rays I, 8 (26), I, 9 (2) (modally I, 8); P rays 18 (15), 19 (32), 20 (9) (usually 18-19); V rays I, 5 (28). D1 always with 2 nd spinous ray longest especially in adult male, and the rear tip of D1 extending to base of 2nd to 6th branched rays of D2 when depressed in male; and almost reaching or just beyond origin of D2 when depressed in female. Origin of A inserted below the middle vertical line of 1 st and 2nd branched rays of D2. The rear tip of D2 rays when depressed always beyond the procurrent rays of $\mathrm{C}$ in male but not reaching this point in female. $\mathrm{P}$ large and oblong, its rear extension always close to but not reaching vertical through anus in male, but far from this vertical in female. $\mathrm{V}$ disc rounded, spinous rays with pointed membranous lobe, the 1st branched ray longer than the spinous ray. C elliptical, rear edge rounded. 


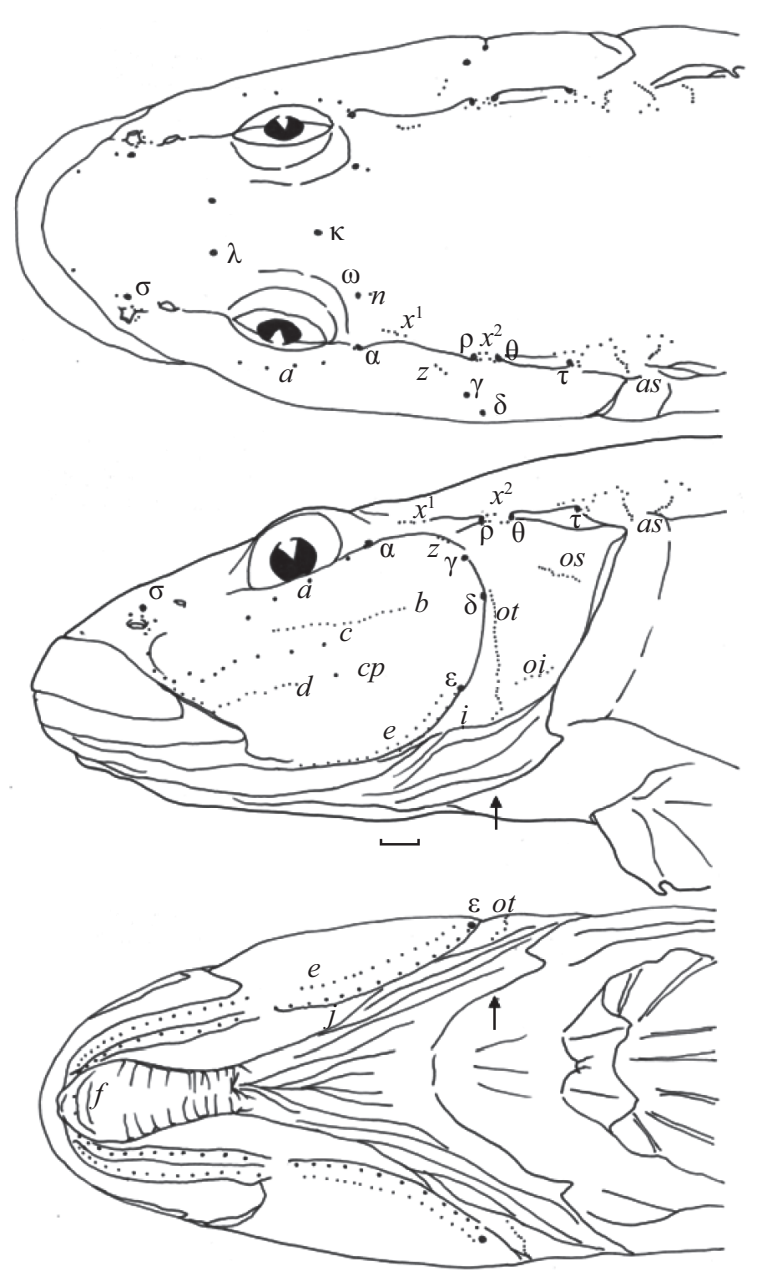

Fig. 1. Head lateral-line system of Rhinogobius ogasawaraensis, OMNH-P 8263, male, paratype, $51.7 \mathrm{~mm}$ SL. Bar $=1 \mathrm{~mm}$. (Illustration by I-S. Chen)

Scales. - Body with moderately large ctenoid scales on posterior body and smaller cycloid scales on anterior half. Belly with tiny cycloid scales. Anterior predorsal region naked. LR 31 (1), 32 (14), 33 (25), 34 (14), 35 (2) (usually 32-34); TR 11 (20), 12 (8) (modally 11); PreD 7 (1), 8 (4), 9 (2), 10 (4), 11 (2), 12 (3), 13 (4), 14 (4), 15 (2), 16 (2); SDP 9 (1), 10 (16), 11 (11) (modally 10). Head and prepelvic region naked. Predorsal squamation with trifurcate anterior edge and anterior extension of middle series usually extending to the vertical through upper origin of gill-opening in male, and usually with further extension forward around the midline vertical of opercle in female.

Head lateral-line system. (Fig. 1) Canals. - Nasal extension of anterior oculoscapular canal with terminal pore $\sigma$ located above the cross-line of rear margin between two anterior nostrils. Anterior interorbital sections of oculoscapular canal separated, with paired pore $\lambda$. A single pore $\kappa$ in posterior region. Pore $\omega$ present near posterior edge of eye. Lateral section of anterior oculoscapular canal with corner pore $\alpha$ and
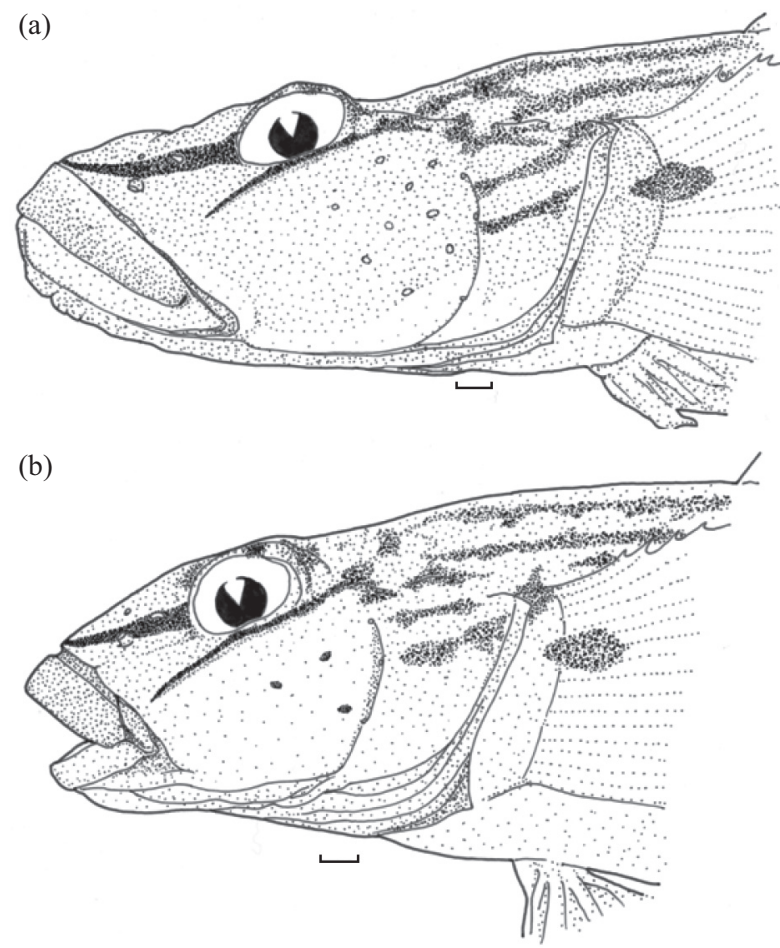

Fig. 2. Head pigmentation pattern of Rhinogobius ogasawaraensis, (a) male, OMNH P8272, paratype, $53.8 \mathrm{~mm} \mathrm{SL}$; (b) female, NTOU P2007-02-883, paratype, $46.5 \mathrm{~mm} \mathrm{SL}$. Bar $=1 \mathrm{~mm}$. (Illustration by I-S. Chen)

terminal pore $\rho$. Posterior oculoscapular canal with two terminal pores $\theta$ and $\mathrm{t}$. Gap between anterior and posterior oculoscapular canals somewhat smaller than the length of posterior oculoscapular canal. Preopercular canal present, with three pores $\gamma, \delta$, and $\varepsilon$.

Sensory papillae. - Row a longitudinal and loosely arranged and extending forward near the vertical through anterior margin of orbit. Row $b$ longitudinal and very long as densely set and the length about 1.5 times of orbit diameter. Rows $c$ and $d$ longitudinal and long, but still not extending beyond vertical line of rear margin of orbit. A single $c p$ papilla. Row $f$ paired. The anterior edge of opercular rows $o i$ and $o t$ well separated.

Colouration when fresh. (Figs. 2-5) Body and head light brown to brown. Head light brown to brown. Cheek with 6-10 orange red spots in male, and less than 5 blackish brown to brownish red spots in female. Snout with a pair of broad deep red stripes united on the snout tip. A red to brownish red oblique thin stripe below eye with lower shiny blue margin. Opercle pale brown with two horizontal deep brown stripes on upper region. Nape with several longitudinal reddish brown to deep brown stripes. Branchiostegal membrane without shiny spots and marks in both sexes. Lateral body with a middle series of 8 somewhat rounded grayish brown blotches. First dorsal fin grayish with yellowish ante rior region on upper half 


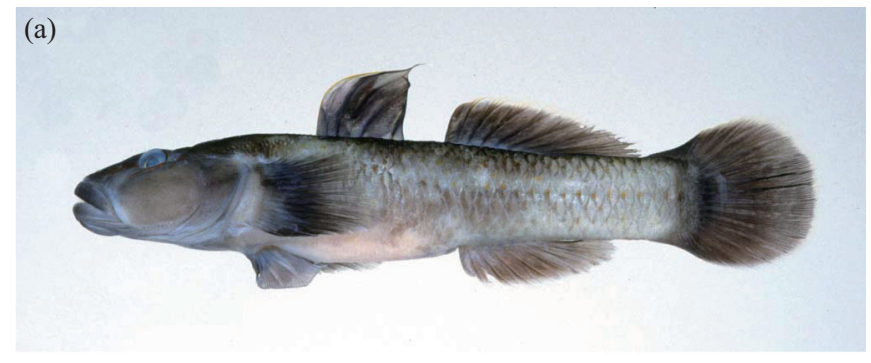

(b)

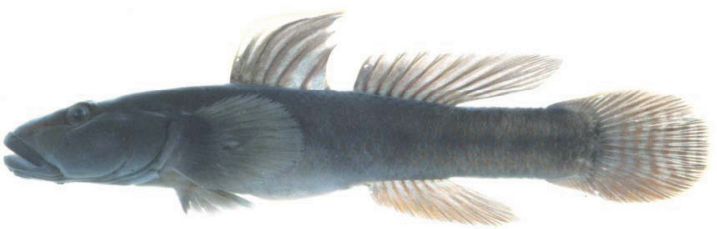

Fig. 3. Rhinogobius ogasawaraensis, fresh specimens, (a) OMNH-P 8278, male, holotype, $65.1 \mathrm{~mm}$ SL; (b) OMNH-P 8262 (KPM-NR 773), male, paratype, $58.3 \mathrm{~mm}$ SL, Yatsusegawa River, Chichijima Island, the Bonin Islands (Ogasawara Group), Japan. (Photograph by $\mathbf{T}$. Suzuki)

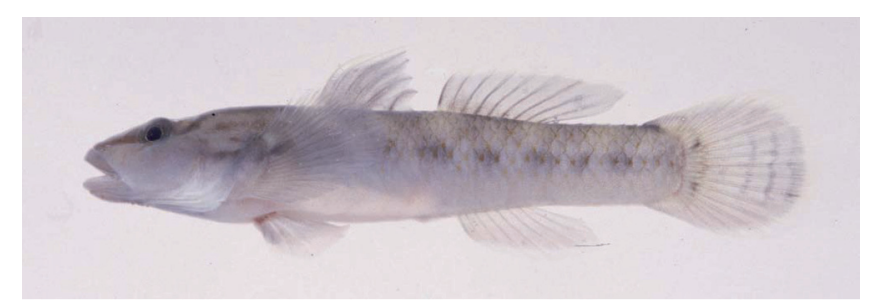

Fig. 4. Rhinogobius ogasawaraensis, fresh specimen, NTOU P 2007-0288-883, female, paratype, $46.5 \mathrm{~mm} \mathrm{SL}$, A small stream of Oki village, Hahajima Island, the Bonin Islands (Ogasawara Group), Japan. (Photograph by T. Suzuki)

of membrane in front of third spine and with deep brown spines. First dorsal fin pale with crescent grayish black region after the spines especially in female. Second dorsal fin with 3-4 longitudinal rows of grayish brown spots in female but always spotless in male. Caudal fin base with a pair of dark brown bars which vertically to each other and more conspicuous larger in female. Caudal fin with 3-5 vertical rows of stripes or spots in middle region. Pectoral fin base with a horizontal, deep black diaper mark in upper half. Anal fin grayish brown with darker rays in male and somewhat translucent and grayish in female. Pelvic fin whitish or grayish brown.

All shiny and brilliant colouration and marks faded after long preservation.

Distribution. This species is only known and possibly merely endemic from Anijima Island, Chichijima Island, Hahajima Island and Otoutojima Island, the Bonin Islands (Ogasawara group), Japan.

Etymology. The specific name, ogasawaraensis, refers to the type locality "Ogasawara Group", Japan.

Ripe egg-size of adult females. From the dissection data of 3 adult female, only two individuals have ripe eggs in their
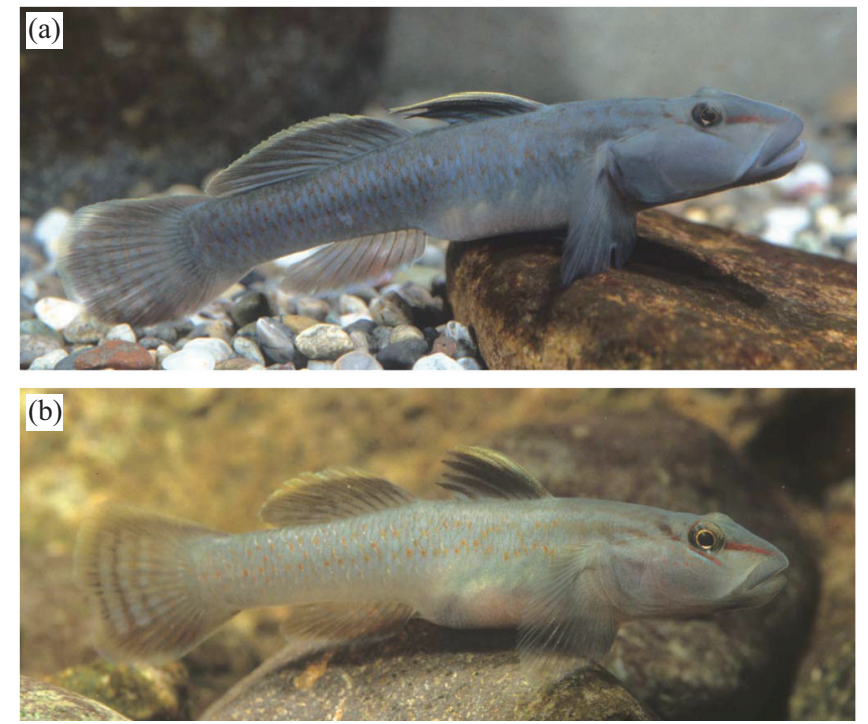

Fig. 5. Alive colouration of Rhinogobius ogasawaraensis, (a) male, OMNH-P 8279; (b) female, OMNH-P 8282. (Photograph by T. Suzuki)

ovaries. This new species was randomly sampled 30 ripe oocytes for measuring the oocyte diameter to be measured and tried to check and estimate the possibility of life history. The ripe oocyte diameter of Rhinogobius osagawaraensis is 0.69 $0.88 \mathrm{~mm}$ as the average $0.77 \mathrm{~mm}$ with standard deviation 0.05 $\mathrm{mm}$. Other comparative studies of four amphirdomous $\mathrm{Rhi}$ nogobius species from Taiwan were also conducted here and also some published and even unpublished comparative data from three amphidromous species of mainland Japan from Tamada ([44, 45]; and personal communication). The size of egg of this new species seems to be close to the range but slightly larger among size range of small-egg species with amphidromous life history from other Taiwanese and Japanese species. However, the size is actually still smaller than other several medium-egg species from Okinawa, Japana and Taiwan (Chen, unpubl. data; Suzuki, unpubl. data). It can be strongly suggested as a typically small-egg amphidromous species.

\section{DISCUSSION}

\section{Morphological Comparison of Related Nominal Rhinogobius Species}

Rhinogobius ogasawaraensis can be shared the common features as typically longitudinal infraorbital sensory papillae, trifurcate anterior margin of predorsal squamation, snout with red to brownish red stripes on snout, rounded pelvic fin with other typical Yoshinobories which can be immediately separated from $R$. giurinus with transverse infraorbital papillae.

$R$. ogasawaraensis can be well distinguished from fluvial species, $R$. flumineus by pectoral fin rays $18-20$, and vertebral counts 26 vs. pectoral fin rays $15-17$, and vertebral counts 
usually 27-28. Among them, the species assigned as endemic species of Ryukyu Archipelagos (including $R$. sp. BB, DL, $\mathrm{MO}$, and YB) have been considered as undescribed species; and all Japanese Yoshinobories should be simplified and grouped to eight mainland species (including $R$. sp. BW, BF, $\mathrm{CB}, \mathrm{CO}, \mathrm{DA}, \mathrm{LD}, \mathrm{TO}$ and three morphotypes of OR) of mainland Japan with low vertebral count 26 as following amphidromous or lacustrine Rhinogobius species: six species names as $R$. brunneus (Temmick and Schelegel), $R$. similis Gill, $R$. nagoyae Jordan and Seale, R. kurodai (Tanaka), $R$. katonis (Tanaka) (as the junior synonym of $R$. nagoyae), and $R$. fluviatilis Tanaka from mainland Japan (Chen and Suzuki unpublished data).

Among the morphological comparison of congeneric species with vertebral count 26 from mainland Japan, $R$. ogasawaraensis seems to be most similar to $R$. brunneus (Temminck and Schelegel) (=R. sp. DA). R. ogasawaraensis in having pectoral fin with a horizontal deep brown mark on upper base, and lacking any patches of dark dots on dorsal side of body vs. $R$. brunneus (Temminck and Schelegel) in having pectoral fin with a crescent shaped deep brown mark on base, and four saddle shaped patches of deep brown dots on dorsal side of body. Compared to other remaining nominal and undescribed species, $R$. ogasawaraensis is distinguished from $R$. sp. CB from mainland Japan by cheek without wavy or radiating lines from eye but presence of orange red spots vs. cheek with many wavy or radiating lines from eye; $R$. ogasawaraensis is distinguished from $R$. sp. CO by cheek with orange red spot but lacking cobalt blue spots, and caudal fin with some dotted deep brown rows on middle region vs. cheek merely with several cobalt blue spots, and caudal fin with blackish brown rays; $R$. ogasawaraensis is distinguished from $R$. fluviatilis Tanaka ( $=R$. sp. LD) by caudal fin with a pair of dark brown bars which vertically each other and some dotted deep brown rows on middle region vs. caudal fin with a distinct vertical blackish brown band on base and deep gray rays; $R$. ogasawaraensis is distinguished from $R$. kurodai Tanaka, morphotype "Gi-tohsyoku" (=R. sp. OR "Gi-tohsyoku") and $R$. sp. BF by first dorsal fin with elongated spinous rays in male vs. first dorsal fin without elongated spines in male; and $R$. ogasawaraensis is distinguished from $R$. kurodai Tanaka, morphotype "Shinjiko" and "Tohshoku" (R. sp. OR morphotype "Shinjiko" and "Tohshoku") by caudal fin in lacking a large orange mark and deep brown rays vs. caudal fin with a large orange mark on upper basal region and deep brown rays; $R$. ogasawaraensis is distinguished from Biwa Lake endemic $R$. sp. BW by 7-16 predorsal scales vs. always lacking predorsal midline squamation; and $R$. ogasawaraensis is distinguished from $R$. sp. TO by the presence of normal preopercular canal with 3 pores vs. complete reduction and absence of preopercular canal (Akihito et al. [2]; Suzuki [35, 36]; Suzuki et al. [39]; Suzuki and Sakamoto [40]; Yokoi and Hosoya [52]).

Among the comparison with nine endemic species of Rhinogobius from Taiwan, $R$. ogasawaraensis shares the overall similarity of typically well developed canal system, high pectoral fin rays counts, low vertebral count 26 as well as reproducing small egg-size with following four nominal species: $R$. formosanus Oshima, $R$. gigas Aonuma and Chen, $R$. lanyuensis Chen et al., and $R$. maculafasciatus Chen and Shao. However, it can be well distinguished from $R$. formosanus by cheek and body coloration pattern. $R$. ogasawaraensis seems shared the homology of spotted cheek in male with the remaining three Rhinogobius species of Taiwan mentioned above. However, R. ogasawaraensis can be easily distinguished from these three species by pectoral fin with a dark horizontal bar; unlike that with three vertical lines in both $R$. gigas Aonuma and Chen and $R$. lanyuensis Chen et al., and that with a dark brown to red vertical stripe or dotted line in $R$. maculafasciatus Chen and Shao.

\section{The Egg-Size Comparison among Amphidromous Rhinogobius Species of Japan}

In Bonin islands (Ogasawara Group) of Japan, the endemic $R$. ogawaraensis seems to represent the larger oocyte diameter $0.77 \mathrm{~mm}$ than any other amphidromous species of mainland Japan with smaller oocyte diameter from 0.53 (for $R$. sp. $\mathrm{CO})-0.72$ (for $R$. brunneus) mm (Tamada [43, 44]). However, such size of diameter in $R$. ogawaraensis seems to be quite smaller than the egg-size of all typical "medium-egg species/morphotype" of both Taiwanese and Japanese freshwaters (Chen, unpubl. data; Suzuki, unpubl. data).

The species origin of endemic $R$. ogasawaraensis may colonize by occasional dispersal of ancestral amphidromous species with long duration postlarval stage. It is very interesting that $R$. ogasawaraensis is not directly evolved from all members of amphidromous Rhinogobius species of mainland Japan by mitogenetic survey (Mukai et al. [30]), but highly possibly shared common ancestor with other certain species group which far from the Ryukyu isles of Japan, Taiwan or even the Philippines then via the northward dispersal process by Kuroshio current. However, this evolutionary hypothesis will be proved by the further more molecular phylogenetic approach including more comprehensive species among those geographical regions (Chen et al., in prep.).

The currently larger oocyte of $R$. ogasawaraensis may lead to produce its shorter postlarval duration and it would be provided positively impact on good chance of success for locating larval populations nearby the coastal area and then ascending to insular basins while growing and help better achievement on efficient life-history of small-scale amphidromy. Due to already on the red-list of freshwater fish in Japan for such very restricted populations of endemic goby: $R$. ogasawarensis under the tentatively name as $R$. BI morphotype before (Suzuki [37]), the serious concern for protecting the original vegetation along river bank and natural river channels would be very important to maintain the annually essential recruitment of their larval fish ascending migration to freshwaters to complete their amphidromy in the Bonin islands (Ogasawara Group). 


\section{Comparative Materials}

\section{1) JAPAN}

Rhinogobius flumineus: OMNH-P 5628 \& 5629, 2 specimens, 43.0-51.8 mm SL, 4 May 1991, Yubune River, Hyogo Pref., Japan; OMNH-P 11929 \& 11930, 2 specimens, 42.643.1 mm SL, 27 August 1997, Kako River, Hyogo Pref., Japan; OMNH-P 12460, 1 specimen, 33.9 mm SL, 11 June 1997, Tigusa River, Hyogo Pref., Japan; OMNH-P 12795 \& 12796, 2 specimens, 40.2-41.4 mm SL, 12 September 1998, Ibana River, Hyogo Pref., Japan; OMNH-P 13296, 1 specimens, 44.4 SL, 21 August 1998, Ibo River, Hyogo Pref., Japan; OMNH-P 15256 \& 15257, 2 specimens, 36.4-38.3 mm SL, 28 October 1994, Maruyama River, Hyogo Pref., Japan; OMNH-P 15959 \& 15960, 2 specimens, 43.2-46.5 mm SL, 25 July 2002, Yura River, Kyoto Pref., Japan; OMNH-P 18355 \& 18356, 2 specimens, 54.5-58.0 mm SL, 26 May 2003, Mizukoe River, Osaka, Japan; OMNH-P 18407 \& 18408, 2 specimens, 53.556.9 mm SL, 20 October 2003, Takatsu River, Shimane Pref., Japan; OMNH-P 21183, 1 specimen, 34.8 mm SL, 27 October 2005, Hidaka River, Wakayama Pref., Japan; OMNH-P 32002, 1 specimen, 45.5 mm SL, 7 March 2006, Kumozu River, Mie Pref., Japan; OMNH-P 32003 \& 32004, 2 specimens, 41.9$44.1 \mathrm{~mm}$ SL, 6 May 2001, Ina River, Hyogo Pref., Japan.

Rhinogobius giurinus: OMNH-P 5760 \& 5761, 2 specimens, 30.8-31.5 mm SL, 16 June 1991, Yada River, Hyogo Pref., Japan; OMNH-P 7890 \& 7891, 2 specimens, 24.2- 26.7 mm SL, 7 May 1994, OMNH-P 7960 \& 7961, 2 specimens, 63.3-74.8 mm SL, 4 September 1994, Sazu River, Hyogo Pref., Japan; OMNH-P 11892 \& 11893, 2 specimens, 42.4-46.6 mm SL, 12 August 1997, OMNH-P 11903 \& 11904, 2 specimens, 39.0-49.0 mm SL, 17 August 1997, OMNH-P 12171, 1 specimen, 51.4 mm SL, 16 October 1997, OMNH-P 15679, 1 specimen, 59.5 mm SL, 9 June 2002, Kako River, Hyogo Pref., Japan; OMNH-P 12846, 1 specimen, 39.4 mm SL, 14 May 1999, OMNH-P 12863, 1 specimen, $60.5 \mathrm{~mm}$ SL, 13 May 1999, OMNH-P 14918, 1 specimen, 46.9 mm SL, 28 August 1999, Maruyama River, Hyogo Pref., Japan; OMNH-P 13348 , 1 specimen, 61.8 mm SL, 18 August 1998, OMNH-P 16014, 1 specimen, 42.4 mm SL, 1 September 2002, Ibo River, Hyogo Pref., Japan; OMNH-P 32000 \& 32001, 4 specimens, 34.9$57.1 \mathrm{~mm}$ SL, 14 October 2000, Umeda River, Aichi Pref., Japan.

Rhinogobius sp. CB: (types of Ctenogobis katonis), ZUMT 2002, holotype, 60.0 mm SL, Kanazawa, Kaga, Japan; ZUMT 57509-11, paratypes, 3 specimens, 43.7-56.8 mm SL, all other data as holotype; OMNH-P 12778, 1 specimen, $38.7 \mathrm{~mm} \mathrm{SL}$, 12 September 1998, Sumoto River, Hyogo Pref., Japan; OMNH-P 12784-12786, 3 specimens, 35.7-48.8 mm SL, 12 Sep-tember 1998, Ibana River, Hyogo Pref., Japan; OMNH-P 15234-15236, 3 specimens, 48.8-57.7 mm SL, 15 September 1995, Maruyama River, Hyogo Pref., Japan; OMNH-P 15244 \& 15245, 2 specimens, 37.8-51.7 mm SL, 4 September 1994, Sazu River, Hyogo Pref., Japan; OMNH-P 15252, 1 specimen, 59.4 mm SL, 11 November 1993, Takeno River,
Hyogo Pref., Japan; OMNH-P 15253-15255, 3 specimens, 50.1-67.4 mm SL, 28 October 1994, Maruyama River, Hyogo Pref., Japan; OMNH-P 21179-21181, 10 specimens, 39.3-58.4 mm SL, 27 October 2005, Hidaka River, Wakayama Pref., Japan; OMNH-P 32108 \& 32109, 2 specimen, 45.2-45.6 mm SL, 5 May 1985, Seto River, Shizuoka Pref., Japan.

Rhinogobius sp. CO: OMNH-P 11588, 11589, \& 11591, 3 specimen, 51.3-68.9 mm SL, 17 September 1998, Nakatsu River, Hyogo Pref., Japan; OMNH-P 11590, 1 specimen, 77.1 mm SL, 17 September 1998, Ai River, Hyogo Pref., Japan; OMNH-P 18426-18428, 3 specimens, 48.4-62.9 mm SL, 24 October 2003, Nabeno River, Kagoshima Pref., Japan; OMNH-P $21177 \& 21178,2$ specimens, 48.0-51.0 mm SL, 27 October 2005, Hidaka River, Wakayama Pref., Japan; OMNH-P 3211032112, 10 specimen, 49.4-72.0 mm SL, 15 September 1981, Nishiurakawachi River, Shizuoka Pref., Japan; OMNH-P 32113 \& 31999, 2 specimen, 35.8-46.5 mm SL, 9 June 2001, Nigo River, Hirosima Pref., Japan.

Rhinogobius brunneus (= R. sp. DA): RMNH 1923, holotype, $46.0 \mathrm{~mm}$ SL, Nagasaki Bay, Japan; OMNH-P 8221 \& 8222, 2 specimens, 31.6-34.1 mm SL, 14 September 1998, Honjyu River, Hyogo Pref., Japan; OMNH-P 8230 \& 8235, 2 specimens, 34.1-67.8 mm SL, 14 September 1998, Oo River, Hyogo Pref., Japan; OMNH-P 8236-8240, 5 specimens, 52.5$66.8 \mathrm{~mm}$ SL, 14 September 1998, Habu stream, Hyogo Pref., Japan; OMNH-P 8241, 7 specimens, 46.3-57.2 mm SL, 12 September 1998, Sumoto River, Hyogo Pref., Japan; OMNH-P 11583 \& 11584, 2 specimens, 59.3-65.4 mm SL, 16 September 1998, Mihara River, Hyogo Pref., Japan; OMNH-P 12781, 12782, 12788 \& 12789, 4 specimens, 47.2-59.0 mm SL, 12 September 1998, Ibana River, Hyogo Pref., Japan; OMNH-P 12808-12810, 3 specimens, 33.0-40.6 mm SL, 14 September 1998, Honjyu River, Hyogo Pref., Japan; OMNH-P 15248, 1 specimen, 78.0 mm SL, 1 September 1994, Sazu River, Hyogo Pref., Japan; OMNH-P 15249, 1 specimen, 69.1 mm SL, 29 August 1993, Nishi River, Hyogo Pref., Japan; OMNH-P 32106 \& 32107, 2 specimen, 46.1-50.7 mm SL, 29 July 1985, Suzuri River, Shizuoka Pref., Japan.

Rhinogobius fluviatilis (= R. sp. LD): ZUMT 9108, holotype, $74.5 \mathrm{~mm}$ SL, Himenji, Hyogo Prefecture, Japan; OMNH-P 11585-11587, 3 specimens, 52.1-64.5 mm SL, 16 September 1998, Mihara River, Hyogo Pref., Japan; OMNH-P 1279112793, 3 specimens, 34.9-57.0 mm SL, 12 September 1998, Ibana River, Hyogo Pref., Japan; OMNH-P 15251, 1 specimen, 59.0 mm SL, 29 August 1993, Nishi River, Hyogo Pref., Japan OMNH-P 18391-18394, 4 specimens, 70.1-86.2 mm SL, 9 September 2003, Komenotsu River, Kagoshima Pref., Japan; OMNH-P 18429, 1 specimen, 69.8 mm SL, 24 October 2003, Nabeno River, Kagoshima Pref., Japan; OMNH-P 18436, 1 specimen, 83.9 mm SL, 31 October 2003, Kuzuryu River, Fukui Pref., Japan; OMNH-P 21175, 21176, 21182, 4 specimens, 54.4-72.0 mm SL, 27 October 2005, Hidaka River, Wakayama Pref., Japan; OMNH-P 32104, 32105 \& 32114, 10 specimens, 44.9-66.7 mm SL, 15 October 1984, Seto River, Shizuoka Pref., Japan; OMNH-P 32115-32117, 3 specimens, 
63.0-70.5 mm SL, 4 September 1995, Kuzuryu River, Fukui Pref., Japan.

Rhinogobius kurodai morphotype "Gi-tohsyoku" (=R. sp. OR morphotype "Gi-tohsyoku"): (types of Ctenogobius kurodai), ZUMT 2008, holotype, 33.9 mm SL, 27 Sept. 1908, Freshwater pond in garden of Marquis Kuroda, Tokyo, Japan; ZUMT 2009, paratypes, 10 specimens, 20.6-28.9 mm SL, all other data as holotype; OMNH-P 32013-32015, 3 specimens, 36.1-40.4 mm SL, 4 June 2002, Tama River, Tyokyo, Japan; OMNH-P 21132-21136, 5 specimens, 37.3-46.8 mm SL, 20 June 2005, Shiratori Moat, Tyokyo, Japan.

Rhinogobius kurodai morphotype "Shinjiko" (=R. sp. OR morphotype "Shinjiko"): OMNH-P 5441 \& 5442, 2 specimens, 53.3 \& $53.9 \mathrm{~mm} \mathrm{SL}, 26$ October 1994, OMNH-P 5411-5415, 7 specimens, 56.5-70.7 mm SL, 11 November 1994, OMNH-P 5416, 5417 \& 5419, 3 specimens, 49.1-56.5 mm SL, 12 November 1994, OMNH-P 5423, 15 specimens, 44.7-58.0 mm SL, 15 November 1994, Maruyama River, Hyogo Pref., Japan.

Rhinogobius kurodai morphotype "Toshoku" (=R. sp. OR morphotype "Toshoku”): OMNH-P 32005-32009, 5 specimens, 41.7-52.9 mm SL, 19 November 1996, Yasu River, Shiga Pref., Japan; OMNH-P 32010 \& 32011, 2 specimens, 35.6, $43.7 \mathrm{~mm}$ SL, 29 July 2001, Hino River, Shiga Pref., Japan; OMNH-P 32012, 1 specimen, 65.2 mm SL, 18 September 2002, Jyasa River, Shiga Pref., Japan.

Rhinogobius sp. BF: OMNH-P 5882 \& 5883, 2 specimens, 27.9 \& 37.0 mm SL, 18 March 1995; OMNH-P 5890-5892 \& 8033-8037, 8 specimens, 25.7-37.4 mm SL, 24 March 1995; OMNH-P $8076 \& 8077,2$ specimens, $30.0 \& 35.0 \mathrm{~mm} \mathrm{SL}, 15$ September 1995, Maruyama River, Hyogo Pref., Japan.

Rhinogobius sp. BW: BLIH 20010402-20010408, 11 specimens, 29.1-35.2 mm SL, 1 July 2001, Lake Biwa, Shiga Pref., Japan.

Rhinogobius sp. TO: BLIH 20000256-20000267, 14 specimens, 28.3-37.8 mm SL, 1 April 2000, Yahagi River, Aichi Pref., Japan; BLIH 20000268, 1 specimen, 28.7 mm SL, 1 April 2000, Toki River, Gifu Pref., Japan; BLIH 20000269, 4 specimens, 26.8-32.8 mm SL, 13 September 2000, Pond of Nagakute Cho, Aichi Pref., Japan; BLIH 20010400, 1 specimen, $30.7 \mathrm{~mm} \mathrm{SL}, 6$ April 2001, Pond of Toyokawa city, Aichi Pref., Japan; BLIH 20010401, 1 specimen, 33.0 mm SL, 13 November 2001, Ibi River, Gifu Pref., Japan.

\section{2) TAIWAN}

All examined materials of nine nominal species of $R h i-$ nogobius from Taiwan are listed in Aonuma and Chen [3], Chen, Miller and Fang [12] and Chen and Shao [13].

\section{ACKNOWLEDGMENTS}

We are very grateful to G. Fukagawa (Nagasaki Food Hygiene Assciatio), K. Hatooka (OMNH), A. Iwata (Kyoto University), T. Mukai (Gifu University) for their kind cooperation in the present study. We are also very grateful to $\mathrm{K}$.
Tamada (Toyo Public Junior High School, Japan) for his kindly providing his unpublished oocyte data of Rhinogobius brunneus for the comparison of this research. ISC wishes to thank the support from the research grant of NSC, Taipei.

\section{REFERENCES}

1. Akihito, Prince, Hayashi, M., and Yoshino, T., "Suborder Gobioidei," in: Masuda, H., Amaoka, A., Araga, C., Uyeno, T., and Yoshino, T. (Eds.), The Fishes of the Japanese Archipelago, Tokai University Press, Tokyo, pp. 228-289 (1984).

2. Akihito, Sakamoto, K., Ikeda, Y., and Sugiyama, K., "Gobioidei," in Nakabo, T. (Ed.), Fishes of Japan with Pictorial Keys to the Species, 2nd English Edition, Tokai University Press, Tokyo, pp. 1139-1310, 15961619 (2002).

3. Aonuma, Y. and Chen, I-S., "Two new species of Rhinogobius (Pisces, Gobiidae) from Taiwan,” Journal of Taiwan Museum, Vol. 49, pp. 7-16 (1996).

4. Chen, I-S. and Fang, L. S., The Freshwater and Estuarine Fishes of Taiwan, National Museum of Marine Biology and Aquarium Press, Pingtung (1999). (in Chinese)

5. Chen, I-S. and Fang, L. S., "A new species of Rhinogobius (Teleostei: Gobiidae) from the Hanjiang basin, in Guangdong Province, China," Ichthyological Research, Vol. 53, pp. 247-253 (2006).

6. Chen, I-S. and Kottelat, M., "Rhinogobius maculicervix, a new species of goby from the Mekong basin in northern Laos," Ichthyological Exploration of Freshwaters, Vol. 11, pp. 81-87 (2000).

7. Chen, I-S. and Kottelat, M., "Three new freshwater gobies of the genus, Rhinogobius (Teleostei: Gobiidae) from northeastern Laos," The Raffles Bulletin of Zoology, Vol. 51, pp. 87-95 (2003).

8. Chen, I-S. and Kottelat, M., "Four new freshwater gobies of the genus Rhinogobius (Teleostei: Gobiidae) from northern Vietnam," Journal of Natural History, Vol. 39, pp. 1407-1429 (2005).

9. Chen, I-S., Kottelat, M., and Miller, P. J., "Freshwater gobies the genus Rhinogobius from the Mekong basin in Thailand and Laos, with descriptions of three new species," Zoological Studies, Vol. 38, pp. 19-32 (1999).

10. Chen, I-S. and Miller, P. J., "Redescription of Gobius davidi (Teleostei: Gobiidae) and comparison with Rhinogobius lentiginis," Cybium, Vol. 22, pp. 211-221 (1998).

11. Chen, I-S., Miller, P. J., and Fang, L. S., "A new species of freshwater goby from Lanyu (Orchid Island), off Taiwan," Ichthyological Exploration of Freshwaters, Vol. 9, pp. 255-261 (1998).

12. Chen, I-S., Miller, P. J., Wu, H. L., and Fang, L. S., "Taxonomy and mitochondrial sequence evolution in non-diadromous species of Rhinogobius (Teleostei: Gobiidae) of Hainan Island, southern China," Marine and Freshwater Research, Vol. 53, pp. 259-273 (2002).

13. Chen, I-S. and Shao, K. T., "A taxonomic review of the gobiid fish genus Rhinogobius Gill, 1859, from Taiwan with descriptions of three new species," Zoological Studies, Vol. 35, pp. 200-214 (1996).

14. Chen, I-S., Wu, H. L., and Shao, K. T., "A new species of Rhinogobius (Teleostei: Gobiidae) from Fujian Province, China," Ichthyological Research, Vol. 46, pp. 171-178 (1999).

15. Chen, I-S., Yang, J. X., and Chen, Y. R., “A new species of Rhinogobius (Teleostei: Gobiidae) from the Honghe basin, Yunnan Province," Acta Zoologica Taiwanica, Vol. 10, pp. 45-52 (1999).

16. Gill, T. N., "Notes on a collection of Japanese fishes, made by Dr. J. Morrow," Proceedings of Academy of Natural Sciences Philadelphia, Vol 11 , pp. 144-150 (1859).

17. Ginsburg, I., "On two species of fishes from the Yalu River, China," Proceedings of the United States National Museum, Vol. 54, pp. 99-101 (1917).

18. Herre, A. W. C. T., "Gobies of Philippines and China Sea," Monograph of Bureau Science Manila, Vol. 23, pp. 1-352 (1927).

19. Huang, S. P. and Chen, I-S., "Three new species of Rhinogobius Gill, 
1859 (Teleostei: Gobiidae) from the Hanjiang basin, southern China," The Raffles Bulletin of Zoology Supplements, Vol. 14, pp. 101-110 (2007).

20. Jordan, D. S. and Seale, A., "Descriptions of six new species of fishes from Japan," Proceedings of the United States National Museum, Vol. 30 , pp. 143-148 (1906).

21. Kottelat, M., "Zoogeography of the fishes from Indochinese inland waters with an annotated check-list," Bulletin Zoölogisch Museum, Universiteit van Amsterdam, Vol. 12, pp. 1-55 (1989).

22. Lee, S. C. and Chang, L. T., "A new goby, Rhinogobius rubromaculatus (Teleostei: Gobiidae) from Taiwan,” Zoological Studies, Vol. 35, pp. 3035 (1996).

23. Masuda, H. and Kobayashi, Y., Grand Atlas of Fish Life Modes, Tokai University Press, Tokyo (1994). (in Japanese)

24. Masuda, Y., Ozawa, T., and Enami, S., "Genetic differentiation of among eight color types of the freshwater goby, Rhinogobius brunneus, from western Japan," Japanese Journal of Ichthyology, Vol. 36, pp. 30-41 (1989).

25. Miller, P. J., "New species of Corcyrogobius, Thorogobius and Wheelerigobius from west Africa (Teleostei: Gobiidae)," Journal of Natural History, Vol. 22, pp. 1245-1262 (1988).

26. Mizuno, N., "Description of a new freshwater goby from Japan," Memoirs of the College of Science, Kyoto University (Ser. B), Vol. 27, pp. 117119 (1960).

27. Mizuno, N. and Goto, A., Japanese Freshwater Fishes, and Their Distribution, Variation and Speciation, Tokai University Press, Tokyo, pp. 1-244 (1987). (in Japanese)

28. Mukai, T., Nakamura, S., Suzuki, T., and Nishida, M., "Mitochondrial DNA divergence in yoshinobori gobies (Rhinogobius species complex) between the Bonin Islands and the Japan-Ryukyu Archipelago," Ichthyological Research, Vol. 52, pp. 410-413 (2005).

29. Oijen, M. J. P., Suzuki, T., and Chen, I-S., "On the earliest published species of Rhinogobius. With a redescription of Gobius brunneus Temminck and Schlegel, 1845," Journal of the National Taiwan Museum, Vol. 64, pp. 1-17 (2011)

30. Oshima, M., "Contributions to the study of the fresh water fishes of the island of Formosa," Annals of the Carnegie Museum, Vol. 12, pp. 169328 (1919).

31. Regan, C. T., "The Duke of Bedford's Zoological Exploration in eastern Asia.--VIII. A collection of freshwater fishes from Corea," Proceedings of the General Meetings for Scientific Business of the Zoological Society of London, Vol. 1908, pp. 59-63 (1908a).

32. Regan, C. T., "Description of new fishes from Lake Candidius, Formosa, collected by Dr. A. Moltrecht," Annals and Magazine of Natural History (Series 8), Vol. 2, pp. 358-360 (1908b).

33. Rutter, C. M., "A collection of fishes obtained in Swatow, China, by Miss Adele M. Fielde," Proceedings of the Academy of Natural Sciences of Philadelphia, Vol. 49, pp. 56-90 (1897).

34. Sanzo, L., "Distribuzione delle papille cutanee (organi ciatiformi) e suo valore sistematico nei gobi," Mitteilungen aus der zoologischen Sation zu Neapel, Vol. 20, pp. 249-328 (1911). (in Italian)

35. Suzuki, T., "Preliminary study of Rhinogobius sp. BI collected from Chichijima Island, Ogasawara Islands," Hyogo Rikusui Seibutsu, Vol. 42, pp. 5-12 (1992). (in Japanese)

36. Suzuki, T., "Rhinogobius sp. BI, Ogasawara-yoshinobori," in: Kawanabe, H., Mizuno, N., and Hosoya, K. (Eds.), Revised Freshwater Fishes of Japan, Yama-Kei Publishing Company Ltd, Tokyo, pp. 588-589 (2001). (in Japanese)

37. Suzuki, T., "Rhinogobius sp., Ogasawara-yoshinobori," in: Ministry of the Environment (Ed.), Threatened Wildlife of Japan: Red Data Book 2nd Ed.: Volume 4, Pisces - Brackish and Freshwater Fishes, Wildlife Re- search Center, Tokyo, Japan, pp. 134-135 (2003). (in Japanese)

38. Suzuki, T. and Chen, I-S., "Redescriptions of three species of genus Rhinogobius Perciformes, Gobiidae) described by Dr. Shigeho Tanaka," Bulletin of the Osaka Museum of Natural History, Vol. 65, pp. 9-24 (2011). (in Japanese with English abstract)

39. Suzuki, T., Mukai, T., Yoshigou, H., Oseko, N., and Tyon, D., "Redefinition and proposal of the new standard Japanese name for Rhinogobius sp. OR morphotype "Shimahire" (Perciformes, Gobiidae)," Bulletin of the Osaka Museum of Natural History, Vol. 64, pp. 1-14 (2010). (in Japanese with English abstract)

40. Suzuki, T. and Sakamoto, K., "Record of a gobiid fish, Rhinogobius sp. TO (Perciformes, Gobiidae) from the Noubi and Okazaki plains, Japan," Bulletin of the Biogeographical Society of Japan, Vol. 60, pp. 13-20 (2005). (in Japanese with English abstract)

41. Suzuki, T. and Shibukawa, K., "Genus Rhinogobius," in: Senou, H. (Ed.), A Photographic Guide to the Gobioid Fishes of Japan, Heibonsha, Tokyo, pp. 445-461 (2004). (in Japanese)

42. Takahashi, S. and Okazaki, T., "A new lentic form of the "yoshinobori" species complex, Rhinogobius spp. from Lake Biwa, Japan, compared with lake-river migrating Rhinogobius sp. OR," Ichthyological Research, Vol. 49, pp. 333-339 (2002).

43. Tamada, K., "Clutch size and egg size in three species of Rhinogobius complex dwelling in a single stream," Japanese Journal of Ichthyology, Vol. 48, pp. 49-52 (2001). (in Japanese with English abstract)

44. Tamada, K., "Clutch and egg size in Rhinogobius sp. DA inhabiting small rivers," Japanese Journal of Ichthyology, Vol. 52, pp. 17-20 (2005). (in Japanese with English abstract)

45. Tanaka, S., "Descriptions of eight new species of fishes from Japan," $A n-$ notationes Zoologicae Japonenses, Vol. 7, pp. 27-47 (1908).

46. Tanaka, S., "Figures and descriptions of the fishes of Japan including Riukiu Islands, Bonin Islands, Formosa, Kurile Islands, Korea and southern Sakhalin," Figures and Descriptions of the Fishes of Japan, Vol. 34, pp. 629-644 (1925). (in Japanese and English)

47. Temminck, C. J. and Schlegel, H., "Pisces," Fauna Japonica, Parts 7-9, pp. 113-172 (1845).

48. Wongrat, P. and Miller, P. J., "The innervation of head neuromast rows in eleotridine gobies (Teleostei: Gobiidae)," Journal of Zoology, London, Vol. 225, pp. 27-42 (1991).

49. Wu, H. L. (Ed.), Fauna Sinica, Ostichthys, Perciformes (V) Gobioidei, Science Press, Beijing, pp. 1-952 (2008). (in Chinese)

50. Wu, H. L. and Ni, Y., "Gobiidae," in: Anonnymous (Ed.), The Freshwater and Estuarine Fishes of Hainan Island, Guangdong Sciecne and Technology Press, Guangzhou, pp. 259-314 (1986).

51. Yokoi, K., "Study on the protection for the endangered freshwater goby, Rhinogobius sp. BI. from the Bonin Islands," Memoirs of the Faculty of Agriculture of Kinki University, Vol. 42, pp. 145- 201 (2009). (in Japanese with English abstract)

52. Yokoi, K. and Hosoya, K., "Distribution and present status of the habitat in Rhinogobius sp. BI (Gobiidae) from the Bonin Islands," Bulletin of the Biogeographical Society of Japan, Vol. 58, pp. 1-14 (2003). (in Japanese)

53. Yokoi, K. and Hosoya, K., "Larval salinity tolerance in the endangered goby Rhinogobius sp. BI (Gobiidae) from the Bonin Islands," Japanese Journal of Ichthyology, Vol. 52, pp. 31-34 (2005). (in Japanese with English abstract)

54. Yokoi, K., Sasaki, T., and Suzuki, T., "Ogasawara-yoshinobori (Rhinogobius sp. BI): aspects of the conservation of freshwater ecosystems on oceanic islands," Japanese Journal of Ichthyology, Vol. 56, pp. 67-70 (2009). (In Japanese) 